\title{
A note on the possibility of a reinforcement theory of cognitive learning*
}

\author{
KENDON SMITH \\ University of North Carolina at Greensboro, Greensboro, North Carolina 27412
}

\begin{abstract}
It is suggested that cognitive linkages are formed not by contiguity alone, but by contiguity plus a species of secondary reinforcement. It is also proposed that such linkages, when activated by the environment, result in a surrogate learning experience, the latter being responsible for the overt behavior which then occurs.
\end{abstract}

Considerable support has recently arisen for an essentially neo-Tolmanian view of motivation and learning (e.g., Cofer \& Appley, 1964; Atkinson \& Wickens, 1971; Estes, 1971; Logan, 1971; Bindra, 1972; Bolles, 1972). In general, the elements of that view are: (a) that learning, properly speaking, is the development of new sequential linkages between cognitive events; (b) that such learning occurs by a principle of sheer contiguity; (c) that, although cognition is something fundamentally different from behavior, it acts to guide behavior; and thus (d) that changes in cognitive linkages, as brought about by learning, are reflected in the modification of overt performance.

An approach of this sort has always had a certain phenomenal validity. It has also customarily evoked at least two basic objections. Each will be mentioned briefly below.

The first has had to do with the dependence of the notion upon the principle of pure contiguity. Although it of ten seems as if cognitive linkages can be explained in terms of association alone, there is such an abundance of negative cases as to make the principle highly suspect. Thus, as is often remarked, it is a common experience to have a certain percept, image, or thought followed closely, time and time again, by another one, so that almost unlimited contiguity is provided; and yet to find that the subsequent occurrence of the first cognition will have no tendency at all to evoke the second. The suggestion which often arises from such circumstances is that reinforcement must be involved, somehow, in what appears to be learning by pure association (e.g., Berlyne, 1965, p. 100).

The second objection to the cognitive schema has had to do with the nagging question of how cognition leads, in the end, to overt behavior. Even if it be granted that

\footnotetext{
*This paper was read, in slightly different form, at the 1973 meetings of Division 3 of the American Psychological Association, Montreal, Canada. I wish to thank Laureen S. Martin, E. A. Lumsden, and R. L. Shull for helpful comments during its preparation. I am also indebted to Robert C. Beck of Wake Forest University for having pointed out that some kinship exists between the notions expressed here and those expressed by O. H. Mowrer (e.g., 1960).
}

cognitive processes, and the "expectancies" they generate, are quite behavioral, the mechanism by which an "expectancy" can govern conduct remains obscure. If an "expectancy" is viewed, more traditionally, as being nonbehavioral, the problem becomes even more acute. Both Bindra (1972) and Bolles (1972) have recently made serious efforts to deal with this second objection. Even their arguments do not seem entirely persuasive, however; and the question accordingly persists.

In the present note, I should like to advance somewhat more positively than has usually been done the suggestion that cognitive learning may depend upon reinforcement as well as upon contiguity. Also to be proposed is a mechanism through which cognitive processes might possibly lead to overt behavior. The underlying assumption throughout, it should be emphasized, is that cognitive activity is in fact a kind of behavior. Cognitive events arise as responses to other cognitive events or to extemal stimulation. They serve in turn as stimuli to still further cognitive events or to frankly motoric responses. Functionally speaking, they are embedded in the ongoing stream of behavior and are an intrinsic part of it (Skinner, 1964; Berlyne, 1965; Homme, 1965; Smith, 1969). It is thus to be expected that cognitive events will be subject to the same laws as are other forms of behavior.

Such an orientation has immediate implications for the question of reinforcement in cognitive learning. The latter in particular would be expected to manifest itself in accordance with the rules of learning in general; and it would appear that very little firm evidence has emerged from other areas to indicate that learning can be accomplished by contiguity alone (Smith, 1954; Hilgard \& Bower, 1966, pp. 109-110). Even a priori, then, and aside from the anecdotal evidence already mentioned, one would be inclined to look for reinforcemental factors in cognitive learning and not to expect the latter to proceed, uniquely, by association alone.

There does exist, too, a somewhat more affirmative argument in favor of reinforcement as an element in cognitive learning. The essence of that argument was in fact clearly adumbrated some time ago by R. S. Woodworth (Woodworth, 1947). Woodworth happens to 
have been concerned with the specific cognitive response of perception; all the same, his basic point is one evidently worthy of generalization to other sorts of cognition as well.

As Woodworth himself put it, the heart of his argument was the premise that "... perception is always driven by a direct, inherent motive which might be called the will to perceive. Whatever ulterior motives might be present from time to time, this direct perceptual motive is always present in any use of the senses... To see, to hear-to see clearly, to hear distinctly-to make out what it is one is seeing or hearing ... such concrete, immediate motives dominate the life of relation to the environment [1947, p. 123]."

It is true that many would be dubious about an "inherent ... will to perceive." It is to be noted, however, that Woodworth was willing to recognize "ulterior motives," too; and it would not be difficult to modify his hypothesis somewhat, in the direction thus suggested, to avoid its dependence on anything as problematical as an innate need to perceive. One could simply recognize the fact that verdical perception has great practical utility. In avoiding pain, in finding food or mate, the preliminary response of interpreting sensory input is of obvious value, and the act of perceiving is thus reinforced over and over again. Granting such continual primary reinforcement, we should expect the successful interpretation of sensory input to take on and maintain a strong secondary reinforcement value of its own. Merely to make sense of what we see, hear, or feel would become as rewarding as Woodworth says it is; and it is readily possible to account for such reinforcement without postulating an innate drive to know.

It is clear that Woodworth's general approach could be extended from the realm of perceptual learning to that of associative learning proper. If the act of perception subserves many drives, and can thus be seen as a generalized reinforcer, the act of association surely does so, too, and can thus be seen in the same light. It is useful to the organism in many ways if one percept, image, or idea, as a stimulus, evokes another, as a response. Sequences of such cognitive S-Rs-" "associative chains," if one likes-enable the organism to test, covertly and tentatively, lines of behavior whose overt expression might be protracted, effortful, and even painful. It would be strange if useful cognitive associations did not begin to carry a secondary reward value of their own. Thus, if the environment or the organism's own thought processes imposed upon the organism a pairing of cognitive responses, and if that pairing were of a sort which had been useful in the past, there would arise a secondary reinforcement effect and a corresponding strengthening of the tendency for the one cognitive event subsequently to evoke the other. In brief, and in a different idiom, one might say that the organism's "storage of information" is an operant event; and Stein (oral statement, 1968; cited in Carroll, 1971) has apparently advanced just such a suggestion.
To be noted here is the fact that the foregoing argument specifies "useful" cognitive sequences. If every associative event were reinforcing, the notion being explored now would be vulnerable to the same objection as ordinary cognitive learning theory. It would predict that every cognitive pairing should produce learning; and we know that, in fact, it does not. What must therefore be postulated is a sort of selective secondary reinforcement: a kind of discrimination among associations as to their putative value, and a corresponding variation in degree of reinforcement for differing cognitive $S-R$ bonds. Such a postulate may possibly be prohibitive; if it is, the overall suggestion is clearly vitiated. The point should not be overlooked, however.

Assuming that cognitive linkages are indeed forged in a reinforcemental fashion, how do they come to influence conduct? Briefly, something of the following sort might be suggested.

Within the frame of reference which has now been developed, the organism can be pictured as being possessed of a large number of cognitive S-R habits. When the organism happens to encounter a problem situation, those habits begin to function. The perception of the situation itself typically evokes a learned imaginal response; that, in general, another such response; that, another; and so on. The organism thus emits a series of instrumental cognitive responses. Characteristically, the latter are representations of the overt responses making up some course of action; and, sooner or later, one of the imaged responses finally evokes an imagined punishment or reinforcement.

Such a sequence seems to act as a surrogate learning experience. If it ends up with imaged punishment the corresponding sequence of overt responses is not likely to be made. If it ends up with imaged reinforcement, the likelihood of actual performance is enhanced, quite possibly to the level at which the behavior in question appears explicitly. It is evident, then, that we have at hand a possible explanation for the effects of cognition upon behavior-if it can be regarded as reasonable that an organism can learn from a sequence of its own images.

It is tempting, of course, to think of the organism as "modeling upon its own imagery." But it really seems most likely that, in the end, imagery will explain the efficacy of modeling, rather than vice versa. Hence, our explanation does not seem to lie simply in the direction of modeling.

Another direction does offer at least tentative hope, however. There is now a rather general acceptance of the idea that perception and imagery are essentially similar functions (cf. Neisser, 1972; Zikmund, 1972; McMahon, 1973)-the one occurring in the presence of the defining stimulus situation, the other occurring in its absence. To image a series of events is thus, to some extent, to perceive it. To actually live through a series of events, however, is also to perceive it. It accordingly follows 
that what goes on in the nervous system during imagination is rather like what goes on during actual experience with the corresponding environmental circumstances. Given some latitude in expression, it could be said that to image a series of events produces the same neural changes as would be produced by direct experience with the events themselves.

The balance of the argument is perhaps not difficult to anticipate. It would suggest that the organism has had an experience essentially equivalent to that of behaving overtly and, in the case which is of interest here, being reinforced. Learning has thus occurred, and the effect of that learning has been to link a new series of responses with the problem situation. As the animal is, in fact, still in that situation, the learned responses are cued, and they are carried out.

In this fashion, cognition might possibly give rise to behavior. It is worth noting that it would do so in a completely determinate way, in accordance with the ordinary principles of learning. The notion that there might be some sort of free decision, on the part of the organism, to "use" its cognitive experience would be, in this framework, completely inappropriate.

\section{REFERENCES}

Atkinson, R. C., \& Wickens, T. D. Human memory and the concept of reinforcement. In $R$. Glaser (Ed.), The nature of reinforcement. New York: Academic Press, 1971.

Berlyne, D. E. Structure and direction in thinking. New York: Wiley, 1965

Bindra, D. A unified account of classical conditioning and operant training. In A. H. Black and W. F. Prokasy (Eds.)
Classical conditioning II. New York: Appleton-Century-Crofts, 1972.

Bolles, R. C. Reinforcement, expectancy, and learning. Psychological Review, 1972, 79, 394-409.

Carroll, J. B. Reinforcement: Is it a basic principle, and will it serve in the analysis of verbal behavior? In R. Glaser (Ed.), The nature of reinforcement. New York: Academic Press, 1971.

Cofer, C. N., \& Appley, M. H. Motivation: Theory and research. New York: Wiley, 1964.

Estes, W. K. Reward in human learning: Theoretical issues and strategic choice points. In R. Glaser (Ed.), The nature of reinforcement. New York: Academic Press, 1971.

Hilgard, E. R., \& Bower, G. H. Theories of learning. (3rd ed.) New York: Appleton-Century-Crofts, 1966.

Homme, L. Perspectives in psychology: XXIV. Control of coverants, the operants of the mind. Psychological Record, $1965,15,501-511$.

Logan, F. A. Incentive theory, reinforcement, and education. In $\mathrm{R}$. Glaser (Ed.), The nature of reinforcement, New York: Academic Press, 1971.

McMahon, C. E. Images as motives and motivations: A historical perspective. American Journal of Psychology, 1973, 86,
465-490.

Mowrer, O. H. Learning theory and the symbolic processes. New York: Wiley, 1960.

Neisser, U. Changing conceptions of imagery. In P. W. Sheehan (Ed.), The function and nature of imagery. New York: Academic Press, 1972.

Skinner, B. F. Behaviorism at fifty. In T. W. Wann (Ed.) Behaviorism and phenomenology: Contrasting bases for modern psychology. Chicago: University of Chicago Press,
1964.

Smith, K. Conditioning as an artifact. Psychological Review, $1954,61,217-225$. Reprinted with note in $G$. Kimble (Ed.), Foundations of conditioning and learning. New York: Appleton-Centurv-Crofts, 1967.

Smith, K. Behavior and conscious experience: A conceptual analysis. Athens, Ohio: Ohio University Press, 1969.

Woodworth, R. S. Reinforcement of perception. American Journal of Psychology, 1947, 60, 119-124.

Zikmund, V. Physiological correlates of visual imagery. In P. W. Sheehan (Ed.), The function and nature of imagery. New York: Academic Press, 1972.

(Received for publication May 20, 1974.)

\title{
The effect of septal and amygdaloid lesions on the duration of emotionality in the white rat
}

\author{
MELVIN L. GOLDSTEIN* \\ Indiana University at Kokomo, Kokomo, Indiana 46901
}

\begin{abstract}
The duration of the septal syndrome and the reciprocal relationship of the septal and amygdaloid nuclei in their effect on emotional behavior were investigated. Gross lesions were placed in the septal nuclei and amygalaloid complex, minute lesions were placed in the medial and lateral septal nuclei, and the effects on emotional behavior were measured over a period of 12 days by means of a rating scale. The septal lesions increased emotionality, but the amygdaloid lesions did not decrease emotionality. The locus for the rage syndrome was found in the lateral septal nucleus.
\end{abstract}

*These experiments were conducted at the University of Wisconsin. Preparation of this report was supported, in part, by Grant No. 26-631-32 awarded by the Indiana University Office of Research and Advanced Studies. Charles Borneman, Jr., made the drawings; Rita Martin and Andy Elledge typed the manuscript. The writer wishes to express his appreciation to his wife, Daidee, for her patience and helpful comments.
Lesions of the septal nuclei in the rat produce a behavioral "rage" syndrome which is characterized by an exaggerated startle response, difficulty in handling, and exaggerated "attack" behavior (Brady \& Nauta, 1953, 1955). These effects have been replicated several times 